\title{
Health Disparity in Haiti Due to the Economic System of the Country
}

\section{Edna Aurelus $^{2 *} \mid$ Inelson Saintil ${ }^{1}$}

\section{*Correspondence: Edna Aurelus}

Address: ${ }^{1}$ State Hospital of Haiti, Research field: Community Medicine Physician, Haiti; ${ }^{2}$ Assistant Professor, Wagner College, New York, USA

e-mail $\bowtie$ : edna.aurelus@gmail.com

Received: 08 May 2020; Accepted: 09 June 2020

Copyright: (C) 2020 Aurelus E. This is an open-access article distributed under the terms of the Creative Commons Attribution License, which permits unrestricted use, distribution, and reproduction in any medium, provided that the original work is properly cited.

\section{ABSTRACT}

Haiti's health system is described as a catastrophic situation when compared to other countries in that region, such as Dominican Republic which shares the same island known as Hispaniola and its neighboring country, Cuba. Haiti's population faces both health disparity and health inequity. The country is very vulnerable with regard to its location geographically. The country is constantly affected by natural disaster, for example the 20107.0 magnitude earthquake, which devastated the island, killing roughly 250,000 and 300,000 people, were injured according to Irvin and Horugavye (2012). Most recently the country was faced with another deadly natural disaster, hurricane Mathew in 2016, six years after a devastated earthquake, which crippled the country even more than before the earthquake. Haiti's unemployment rate for 2018 at $13.53 \%$ when compared to Cuba and DR respectively, they have shown $2.26 \%$ and 5.83 . Haiti's high rate of unemployment automatically objectify its population to health inequities, where many Haitians inherited unfairness due to their low socio-economic status.

The information described above has displayed clearly how vulnerable the country is and have shown the economic gap and health disparity that exist within the population. These reports among others are indeed shocking and must be shared in a global sphere in order to figure out a feasible approach that can solve this fatal problem for the Haitian people.

Keywords: Health Disparity, Health Inequity, Vulnerable, Haiti, Health System

\section{Background and Significance}

It was estimated that in 2020 Haiti's population was at 12 million people according to World Bank data. Enquete Mortality, Morbidite et Utilisation des Services (EMMUS VI, 2016, 2017), described the health system in Haiti, as a catastrophic situation when compared to other countries in that region, such as Dominican Republic (DR) and Cuba. The following data were revealed by EMMUS VI, 2016,2017:

- $\quad$ Maternal mortality rate is at 547/100.000 and infants less than 5-year old's mortality rate is at 58 for every 1,000-live birth.

- $\quad$ Only $42 \%$ child birth happens in the hospital setting.

- $\quad$ Only 55\% of infants receive health coverage such as vaccination. 
According to Haiti Enquete Mortality, Morbidite et Utilisation des Services (EMMUS VI, 2016, 2017), $40 \%$ of the population has no access to healthcare for different reasons, such as geographic location where a health care center is not accessible. Haiti's unemployment rate for 2018 at $13.53 \%$ when compared to Cuba and DR respectively, they have shown $2.26 \%$ and 5.83. Haiti's high rate of unemployment automatically objectify its population to health inequities, where many Haitians inherited unfairness within the healthcare system simply because of their low socio-economic status. These health inequities, ultimately resulted in placing those individuals at a higher risk of poor health and vulnerability. According to the United Nation- World Population Prospects, Haiti life expectancy in 2020 was 64.11 years, when compared to Cuba that was 78.89 years and DR that was 74.15 years. Repeatedly, the data display the catastrophic situation the country is experiencing and how it faces disadvantages in the rank of health, economic and social aspect, as it pertains to life expectancy.

\section{Health Disparity}

Haitians face both health disparity and health inequity. Haiti is the second largest island of the Caribbean after Cuba with an estimated of 12 million people. However, only very few people have access to quality healthcare. Although this paper focuses mainly on health disparity, it is imperative that description of the differences between the two terms is explained.

Health disparity is implied in this paper as the inability to access healthcare for people living in Haiti. Whereas, health inequity is mostly rooted in social injustices that make some population groups vulnerable to poor health than other groups (Nieves, 2019). Unfortunately, in a country, such as Haiti where access to healthcare is scarce, people are subjected to poor health and ultimately premature death. These problems usually arise due to the disproportion of commission or maldistribution of wealth. The implication of commission of wealth in the sense of fee for services rendered, can be a systematic problem due to the inequitable distribution of wealth within the country. Some people simply cannot afford their imposed healthcare cost, which conditioned them to live with a myriad of disadvantages within the given society. They often live with multiple health comorbidities, poor sanitary condition, among other issues which often result in despair and eventually death. Beside health and economic instabilities, lack of resources gives rise to other categories of problem, such as social, cultural, political, and infrastructure aspect of the country. Undoubtedly, those mentioned aspects or components are important topics to discuss, however, we will succinctly be focused on the health disparity problem resulted from the lack of resources and generating revenue of the country. The question one must ask, is how can this disparity gap be closed or prevented in a country like Haiti? This question unfortunately, is very hard to tackle, because there is a minimal group of people that controls and monopolizes the country's wealth, therefore, it would require a conscientious mogul within that 
small group with a brilliant idea, willing to share their wealth and execute an action to eradicate health disparity within the country. Such action may require the will and courage for a person to make such contribution and impact within one's society. Although it is not an easy decision, it is believed to be possible. The private sector and the government can collaborate together to analyze one of the biggest priority of the country, which is healthcare. It is a priority that is neglected across the country and it is time for the government and the private sectors that have the capacity to take action mobilize to save this great nation. With a group of legal, business, healthcare team and available funding health disparity can be eradicated. If health disparity does not eradicate in Haiti, the consequences, they face are poor health and short life expectancy.

Haiti faces another downfall in regards to its ecosystem. Almost every year the country experiences a natural disaster, which destroys lives and natural resources. The country is very vulnerable to tropical storms and hurricane due to its location geographically. Additionally, its poor infrastructure imposes the safety of the population when faced with these natural disasters. For example, the 20107.0 magnitude earthquake, which devastated the island, killing roughly 250,000 and 300,000 people, were injured according to Irvin, B \& Horugavye, P (2012). Most recently the country was faced with another deadly natural disaster, hurricane Mathew in 2016, six years after the devastated earthquake, which crippled the country even more than before the 2010 earthquake. The category 4 hurricane killed 600, displaced an estimated 175,500 people who are left to seek refuge in shelters (Thomas, 2017). The country's ecologically fragile situation due to deforestation, overpopulation in one central region, such as Port Au Prince places people at higher risk during natural disaster. Due to these frequent natural disasters, the country faces a lot of infectious diseases, mental health problems as well as lack of economic resources without forgetting the political instability that the country face on a regular basis.

The information described above has proven to us clearly how vulnerable the country is and has shown the economic gap and health disparity that exists in the population. This health disparity is a very critical situation, which is why we came up with this important topic after researching various economic and health data published by Haiti Enquete Mortality, Morbidite et Utilisation des Services (EMMUS VI, 2016, 2017), where they describe how difficult it is for most Haitians to have access to quality healthcare.

\section{Descriptive Tables}

The three descriptive tables exhibited below were retrieved from EMMUS VI, 2016, 2017 report. These tables depicted an urgency in acting and eradicating health disparity. Furthermore, these tables 
bring more awareness in such catastrophic health situation the country is currently facing. Although the tables are decrypted in French, the significance of each table will be described consecutively.

On Table 1 the main reason why people in Haiti do not seek healthcare is due to the healthcare cost. $58 \%$ of the population indicated that they cannot afford healthcare because it is too expensive for them. Table 2 displays how much money was spent from 2012 to 2013 . We can speculate that these funds were mostly the support of the humanitarian relief post the catastrophic earthquake that destroyed and crippled almost the entire country.

Similar increase is noted on Table 3, as it pertains to healthcare investment, however the question one must ask, is why there has always been such health disparity even when it showed that prices available for healthcare needs assessment were elevated. It is vital that transparency of these funds allocation is made public to the donors in order be aware of how distributions of these funds are taking place. In addition to transparency, the team in charge of investing those funds require a minimum of responsibility and ethical sense. These virtues are most important in countries where a great percentage of the country is poor, and the population relies on those who genuinely want to them. It takes courage for one to do the right thing in the absence of imposed supervision and regulation. Such character still exists in mankind, it is a matter of finding the right group of people with a mutual goal, which is providing quality healthcare for all Haitians.

As champions in the healthcare system, remaining indifferent or silent would be a crime to humanity. It is our civic duty to advocate for those in the general population without a voice, who are dying prematurely from diseases such as a simple appendicitis, hypertension among others. These deaths could have been prevented with the appropriate early intervention. Easy access to healthcare and early medical intervention can help save lives. Therefore, available funding and health supplies need to be distributed fairly throughout the country to assure that medical or healthcare settings are properly equipped with required supplies in order to deliver quality care to the population.

\section{Table 1.}

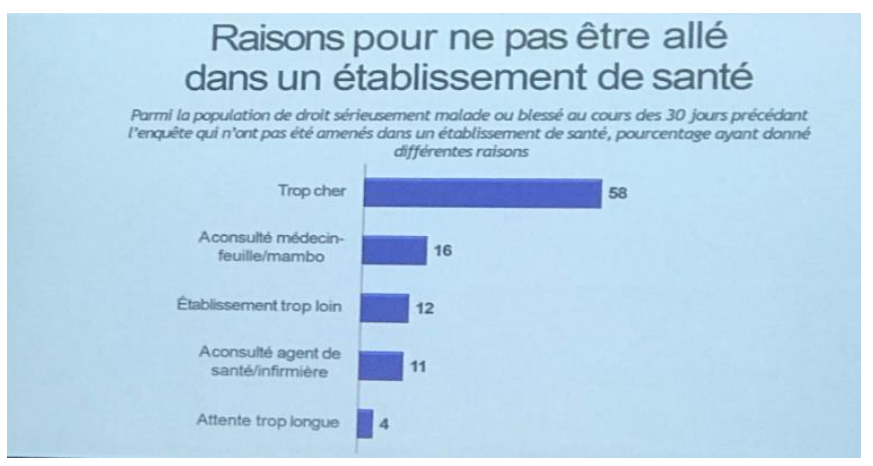




\section{Table 2.}

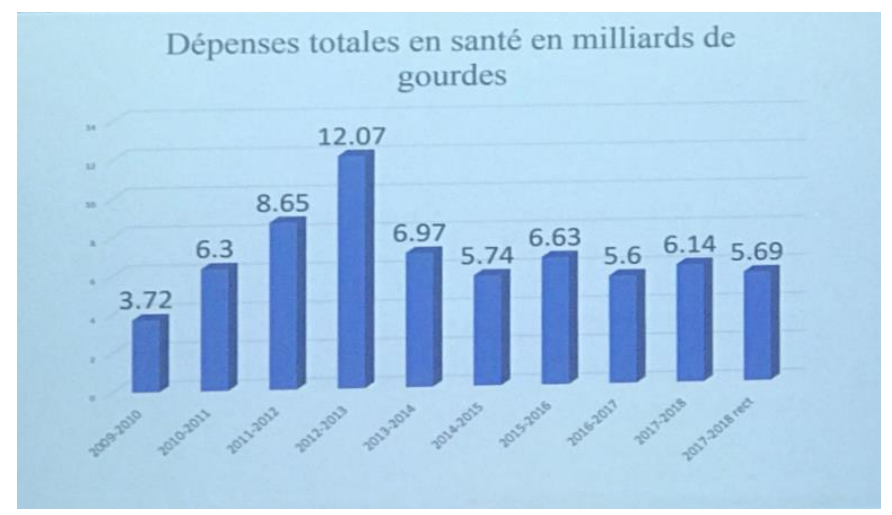

Table 3.

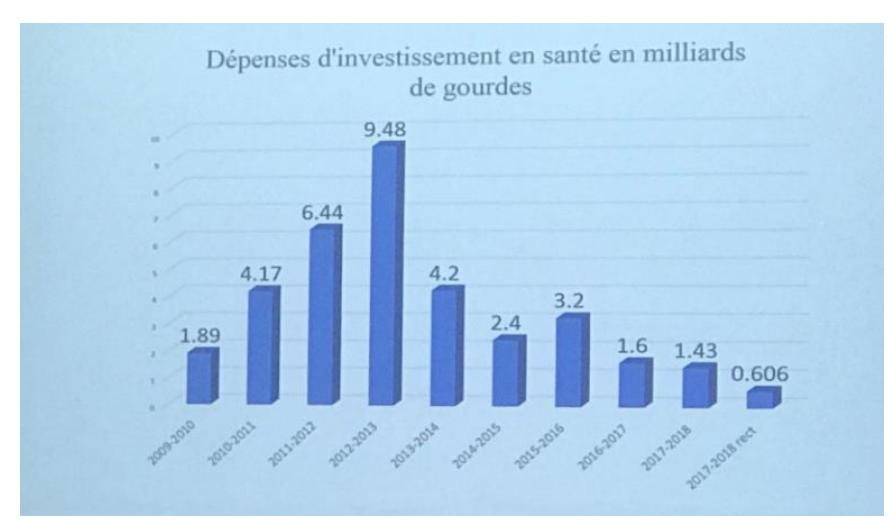

\section{Resolution to the Problem}

We will need the health expertise of other countries that have their healthcare system stable to roadmap guideline that can be useful to our system. Mutual collaboration can be established, where experts from these modeled countries can educate our healthcare administrators and personnel strategic ways to allocate and sustain healthcare resources. The entire healthcare team will be trained on product management, an approach to teach them how to mitigate wasting of health resources and supplies. Additionally, the accountant staff will be oriented by renowned experts on the field on how to budget available funds and medical supplies. Extensive education on how to allocate available funds and distribution of health supplies to each medical institution within the country will be the key component of each training. It is vital that members of the healthcare team are aware of the importance of sustaining resources in order to reach those in need, so that healthcare access can be reachable to everyone within the population. Healthcare access should not be a luxury, no matter what socioeconomic background of a person. 


\section{Conclusion}

It is impossible to end this paper without sharing these statistics. The following numbers do not lie. 124 Communal areas are without healthcare coverage out of 574. Even in those regions where they have available healthcare settings, $60 \%$ of these settings face a lack of medical supplies. Another alarming situation, is the fact that there are 1.58 health professionals for every 1000 people and only $4 \%$ of those 1000 people are able to cover their own healthcare cost (EMMUS VI, 2016, 2017). These reports among others are indeed shocking and must be shared in a global sphere in order to figure out a collective feasible approach that can solve this fatal problem for the Haitian people. Health disparity needs to be eradicated, because healthcare access should be a basic right to all human being and that everyone should be entitled to receive it as needed.

\section{References}

Institut Haïtien de l'Enfance (IHE) et International Classification of Functioning, Disability, and Health (ICF) (2018). Enquête mortalité, morbidité et utilisation des services (EMMUS-VI 2016-2017) (Investigating mortality, morbidity and use of services survey (IMMUS_VI 2016-2017). Pétion-Ville, Haïti, et Rockville, Maryland, USA: IHE et ICF.

Irvin B and Horugavye P. Earthquake response: Final evaluation report. World Vision, 2012.

https://www.worldvision.org/disaster-relief-news-stories/2010-haiti-earthquake-facts

Nieves R. Health disparities vs. health inequities. Boston Public Health Commission, 2019.

https://www.bphc.org/whatwedo/health-equity-social-justice/what-is-health-equity/Pages/Health-Disparities-vs.-HealthInequities.aspx

Thomas A. Two steps back: Haiti still reeling from hurricane matthew. Refugees International, 2017.

https://www.refugeesinternational.org

United Nations. World population prospects, 2020.

https://www.macrotrends.net/countries/HTI/haiti/life-expectancy

World Bank (2020). Haiti unemployment rate 1991-2020. https://www.macrotrends.net/countries/HTI/haiti/unemploymentrate 